\title{
Doing the Right Thing: A Practical Guide to Ethics for Undergraduate Researchers
}

\author{
Moira Maguire*, Brid Delahunt and Ann Everitt-Reynolds \\ Department of Nursing, Midwifery and Health Studies, Dundalk Institute of \\ Technology, Dundalk, Ireland
}

\begin{abstract}
This chapter provides practical support and guidance to students around the ethical dimensions of undergraduate research with human participants. Ethical considerations are perhaps the most important aspect of any research project involving human participants, especially as they speak of the rights of individuals and groups within society. Ethics in research is as much about the process as the final product and emphasis is put on maintaining integrity throughout the life-cycle of the project. Although ethical issues can be challenging, novice researchers are expected to conform to the same principles, standards and norms as more experienced researchers. With this in mind, the principles that guide ethical decision-making are initially outlined and their application to each stage of the research process is subsequently discussed. This discussion is further enhanced through the provision of expert tips and the use of audio clips from students illustrating how ethical issues can be managed within projects.
\end{abstract}

Keywords: Academic integrity, anonymity, confidentiality, data protection, ethical principles, ethical research, informed consent, internet research, ongoing consent, online survey, participants, qualitative research, quantitative research, research process, right of withdrawal, risk of harm, supervision, undergraduate, undergraduate dissertation, undergraduate research.

\section{INTRODUCTION}

Conducting a research project or dissertation offers undergraduate students an excellent opportunity both to make a contribution to knowledge within their chosen discipline and develop an understanding of ethics as applied to real problems. The chapter is aimed primarily at undergraduate students, but may also be useful for tutors new to supervision. The main purpose is to provide practical support and guidance around ethical dimensions of undergraduate research with human participants. Given our own backgrounds in Psychology and Nursing, the

\footnotetext{
*Address correspondence to Moira Maguire: Department of Nursing, Midwifery and Health Studies, Dundalk Institute of Technology, Dundalk, Ireland; Tel: +353 (0) 42 9370200; Fax: +353 (0) 42 9370261; E-mail: moira.maguire@dkit.ie
} 
focus is on issues relevant to typical undergraduate projects in social and health studies. In particular, we consider how to use ethical principles to inform and guide decision-making and behaviour throughout the life-cycle of a project. While the principles are discussed at the beginning of the chapter, their practical application to the research process is integrated in subsequent sections.

\section{What is Ethical Research?}

In research involving human participants, ethical considerations are perhaps the most significant aspects of any project because they speak of the rights (both legal and moral) of individuals and groups within society. Indeed, so sacrosanct are these rights that they form the basis of a myriad of professional, national and international codes and declarations. Sharing a common foundation, namely the protection and respect of human rights and dignity, they outline acceptable and agreed behaviours and standards deemed essential in the design and conduct of research. Although it is beyond the scope of this chapter to review all the individual codes and declarations, it is important to note that formal recommendations in relation to research activity have evolved because of unacceptable and at times reprehensible behaviours and actions in the quest for new knowledge (See Supplementary Material 1: 'Did you know'?).

Hunter (2010, p.18) states that "ethical codes and guidelines are a means of establishing and articulating the values of a particular institution or society and the obligations that it expects people engaged in certain practices to abide by". Perhaps the most frequently cited guidelines in terms of the practice of ethical research involving human participants are those provided by the Belmont Report: Ethical Principles and Guidelines for the Protection of Human Subjects of Research (The National Commission for the Protection of Human Subjects of Biomedical and Behavioural Research, 1979). These guidelines provide the basis for:

a) Contemporary ethical principles and practices in biomedical and behavioural research,

b) Ethical Review Committee protocols and

c) A number of national and international Professional Codes of Conduct (e.g. Ethical Guidelines for Educational Research (British Educational Research Association, 2011), Code of Human Research Ethics 
(British Psychological Society, 2010) and Guidance to Nurses and Midwives Regarding Ethical Conduct of Nursing and Midwifery Research (An Bord Altranais, 2007).

The strength of the Belmont Report is related to the fact that it provides a framework for ethical decision-making by identifying three principles, as summarized in Table 1, all of which are applicable to most research activity irrespective of circumstances, situations or contexts. McCarthy (2003) suggests that the continued dominance of this principlist model to ethical decision-making may be attributed to such notable authors as the bioethicists Tom Beauchamp (who co-wrote the Belmont report) and James Childress. Ongoing revisions of their seminal work, The Principles of Biomedical Ethics, now in its $6^{\text {th }}$ edition, have ensured that ethical principles enshrined in the Belmont Report remain the cornerstone of contemporary research practice. However, it should be acknowledged that the Belmont Report is not without its critics. For example, Miller (2003) argues that the report is too vague, particularly in terms of how the principles relate to each other.

Table 1: Fundamental Ethical Principles

\begin{tabular}{|c|c|c|}
\hline Respect for Persons & Beneficence & Justice \\
\hline $\begin{array}{l}\text { Is concerned with the autonomy } \\
\text { and self- determination of } \\
\text { individuals. } \\
\text { (a) participation in research } \\
\text { should be voluntary } \\
\text { (b) individuals have a right } \\
\text { to full information } \\
\text { about the research in } \\
\text { order to make a } \\
\text { considered judgment to } \\
\text { participate } \\
\text { (c) as autonomous beings, } \\
\text { participants may } \\
\text { withdraw from the study } \\
\text { if they choose } \\
\text { (d) individuals who are } \\
\text { incapacitated or } \\
\text { susceptible to coercion } \\
\text { are entitled to protection }\end{array}$ & $\begin{array}{l}\text { Is concerned with the obligation } \\
\text { of the researcher to: } \\
\text { (a) avoid doing harm } \\
\text { (b) maximising possible } \\
\text { benefits of research } \\
\text { (c) minimising possible or } \\
\text { potential harm } \\
\text { This principle is fundamental } \\
\text { from the individual perspective as } \\
\text { well as society at large as at both } \\
\text { levels an assessment of the risks } \\
v s \text {. the gains in relation to } \\
\text { research is warranted. }\end{array}$ & $\begin{array}{l}\text { Is concerned with who should } \\
\text { reap the rewards of research and } \\
\text { who should 'bear' its burden and } \\
\text { if both the burdens and benefits } \\
\text { are distributed equally: } \\
\text { (a) the selection of participants } \\
\text { should be fair and impartial } \\
\text { (b) the participants should also } \\
\text { be the beneficiaries of } \\
\text { research, particularly if it is } \\
\text { publically funded. }\end{array}$ \\
\hline
\end{tabular}


Increasingly, when discussing or reflecting on ethical research practice, the Responsible Conduct of Research (RCR) is mentioned. This term unites the principles of ethical research (respect for persons, beneficence and justice) and conducting credible or scientifically valid research (using sound methodologies), characterising both as inextricably linked. The responsible conduct of research is defined as "conducting research in ways that fulfil the professional responsibilities of researchers, as defined by their professional organization, the institutions for which they work, and when relevant, the government and public" (Steneck, 2006, p.55). Wrestler (2011) highlights that in terms of the ethical practice of research the process is as important as the final product and so careful consideration should be given to decisions made throughout the course of the study. Perhaps the best way to think about the responsible conduct of research is that the researcher is expected to consciously and judiciously exhibit integrity in relation to all aspects of scientific enquiry. The significance of this has been highlighted in discussion documents such as Ensuring Integrity in Irish Research (Royal Irish Academy, 2010), which promotes agreed national standards in both the conduct of research and procedures for investigating alleged misconduct. Furthermore, this document recommends the establishment of a National Advisory Committee which would develop guidelines and suggest procedures for a research integrity system in Ireland (p.14).

\section{Conducting Ethical Research Studies}

Ethical research with human participants at undergraduate level is no different to ethical research at any other level and thoughtfulness is required. Students are expected to adhere to the same values, principles and norms that govern any researcher in terms of producing ethically 'sound' work. However, it is important to recognise that as an undergraduate researcher the student is a novice within their discipline and should receive support and guidance to develop an ethical project. Every research project is unique and while, typically, undergraduates are not encouraged to work with potentially vulnerable groups or investigate sensitive topics, this does depend on the student and the context of the work. Students differ in terms of skills and competencies in particular areas and both the student 
and supervisor need to assess the student's competence to conduct the research. For example, a student who has childcare qualifications and experience working with children could be in a much better position than a typical student to conduct a project that involves children. It is important to remember that any work with children (or other potentially vulnerable groups) usually requires the researcher to undergo vetting for criminal convictions (see An Garda Síochána (2012) in Ireland and the Criminal Records Bureau (n.d.) in the UK) and this can take some time to complete.

The project itself also matters. Many projects are individual projects, developed by students with support from supervisors. However, increasingly, in many areas, students work as part of a team dealing with a specific aspect of a wider study, perhaps related to the supervisor's own research. Students may well find themselves working on large-scale existing research projects alongside active researchers. Increasingly, many departments encourage students to conduct applied research with community organisations or local businesses. Projects like these often entail the student working on projects that are ethically more challenging (e.g. dealing with a risk of harm or working with vulnerable groups) than the traditional thesis. These projects typically have ethical approval and protocols to be followed. Working on a project like this can be a wonderful learning experience for the student, but it is important to remember that the student is an undergraduate and not a research assistant. These lines can become blurred at times and it is good practice for the student and supervisor to agree what is expected at the start. If a student is unsure about what is being asked it is very important that advice is sought from an appropriate person (e.g. supervisor, personal tutor, head of year or head of department).

\section{Ethics throughout the Research Process}

As ethics are not an 'add on' but rather an integral part of the research process, it is imperative that they are given due consideration from the beginning of the research project. This entails focusing on how ethical principles apply to each stage of the research project (see Fig. 1). This is a good time to review the fundamental ethical principles that merit consideration at appropriate stages of the research process (see Table 1). 


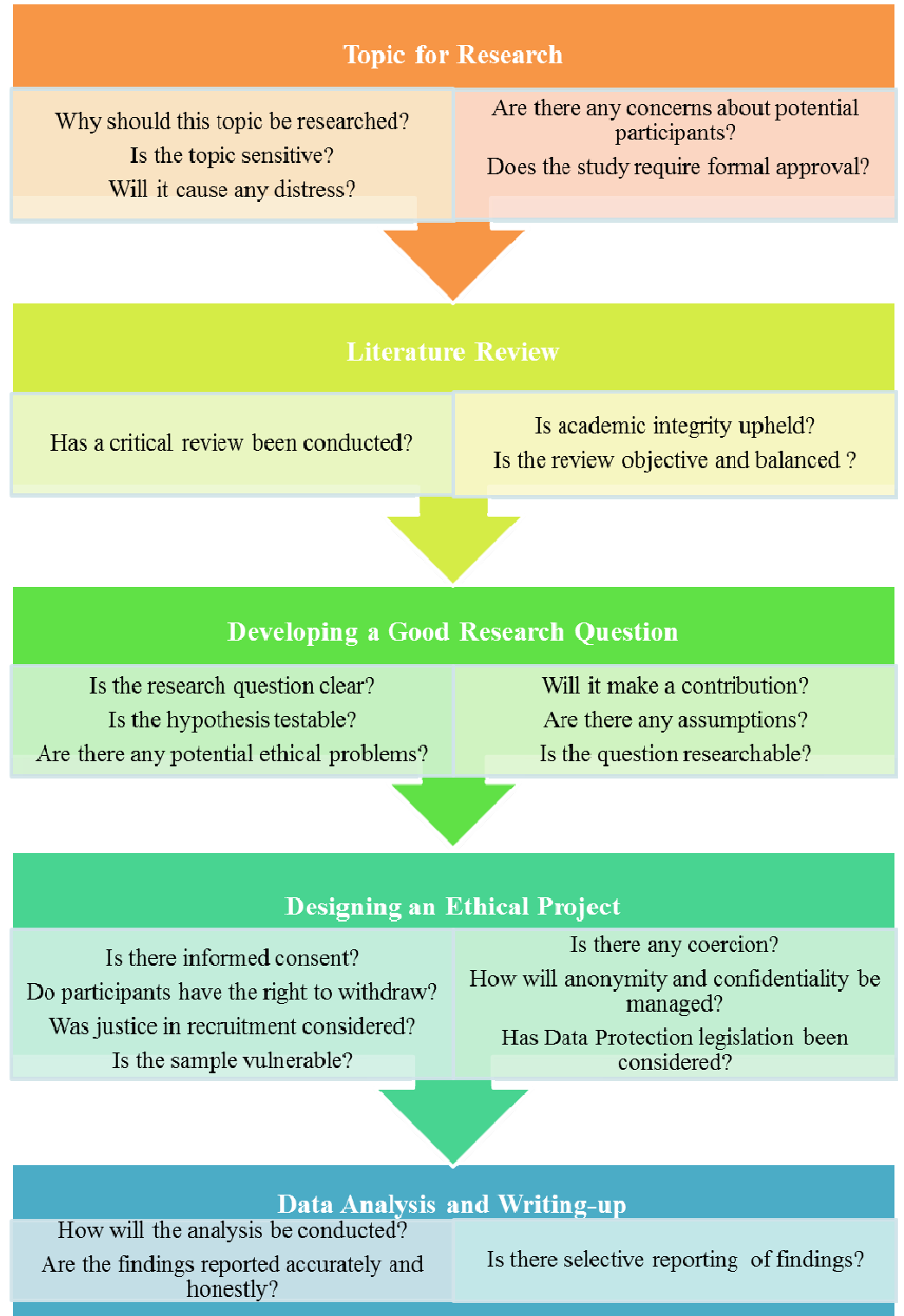

Figure 1: Ethics at each stage of the research project.

\section{Topic for Research}

Before committing to any study it is important that due care and attention are given to potential ethical issues (see Fig. 1). All too often students waste precious time and energy on something of a 'wild goose chase' because the topic is very sensitive or may cause some distress. Sometimes the ethical issues are very obvious and red 
flags are raised from the beginning. For example, a student who volunteers at a Women's Refuge Centre might want to conduct research with some of the women to explore their views about the impact of domestic violence on children. There are obvious issues in terms of the sensitivity of the topic, the vulnerability of the group or potential coerciveness (the women might feel under subtle pressure to participate). Other times, potential ethical issues are more subtle and may only become apparent after discussions with supervisors, peers or colleagues. Too often ethics are not considered at all until after the project has been designed.

\section{Literature Review}

A literature review clarifies the specific problem and helps formulate the research question (see Fig. 1). A key ethical issue here is academic integrity (see Supplementary Material 2: Academic Integrity). It is important to use and report literature in an honest and transparent way and to avoid plagiarism. At undergraduate, as at any other level, the work is expected to add to existing knowledge so a thorough search of the literature should be conducted using appropriate key words. There should be a gap in the literature to provide the impetus for a study. If there is a considerable amount of work on the topic it may be better to consider either another topic or take a different perspective. In relation to the presentation of previous work there are a few points to consider:

1. Studies should be critically evaluated with limitations identified (methodological and ethical).

2. The review should be balanced and objective with studies which both support and oppose the central thesis included.

3. The review should provide a justification for the specific research question.

\section{Developing a Good Research Question}

Developing a good research question is fundamentally an ethical activity (see Fig. 1). The research question should provide insight into actual or potential ethical problems (see Box 1). A good research question provides information on: the research approach (qualitative or quantitative), the study population, the variables 
or constructs of interest and the design that will be used. Hence it draws attention to issues such as vulnerable participants or an intervention that has the potential to cause harm or distress.

CAUTION

\section{Proceed with Extreme Caution if the Research Study:}

- Has the potential to cause any upset or distress.

- Might involve potentially vulnerable groups e.g. minors, prisoners, patients or clients.

- Is concerned with sensitive or potentially sensitive issues, e.g. stress, close personal relationships, bereavement.

- Deals with illegal behaviours or activities.

- Has the potential to cause actual or possible discomfort or physical harm.

\section{Box 1: Thinking about... the topic and the research question}

- Is the question worth asking? No matter how small scale the project or limited the resources, the question should be a worthwhile one if people are to be asked to give up their time to participate.

- Start with the question, not with the sample. Sometimes students really want to do research with a particular group of people, such as small children or patients. This is often because they are very interested in or have access to the population rather than because they have a specific question to ask. It is important to think about this from the perspective of the potential participants - could this be considered exploitative?

- Do you have the skills and competencies necessary to conduct this research?

- What are the potential risks, both to the researcher and participants?

- The acronym RUMBA, widely used in the business and management literature, is a useful aid when phrasing your research question.

Remember a research question should be:

$\mathbf{R}=$ Reasonable/Realistic

$\mathbf{U}=$ Understandable

$\mathbf{M}=$ Measurable or amenable to exploration

$\mathbf{B}=$ Believable

$\mathbf{A}=$ Achievable /Attainable 


\section{Designing an Ethical Project}

Often students say, 'There are no ethical issues with my project', by which they mean that the work is not sensitive, will not involve potentially vulnerable participants and poses no risk of harm. But it is important to note that all work with human participants raises ethical issues that need to be thoughtfully and seriously addressed (see Fig. 1). Therefore, at this point it is important to get the basics right. At a minimum, students need to ensure that participants give free informed consent, have the right of withdrawal and that data collected is stored in an anonymous manner and treated confidentially.

"Competence, information and voluntary-ness are advocated as the 3 key elements of valid informed consent...This to ensure that the person giving consent has the capacity to understand, and sufficient information to enable them to make the decision without duress" (Lambert \& Glacken, 2011, pp.783-84). Consent should be freely given in accordance with the Data Protection Acts (Government of Ireland, 1988/2003). It is important to remember that coercion can be subtle. For example, (a) pressurising friends to act as participants; (b) persuading reluctant participants to come back for a second phase of data collection; (c) expressing disappointment if people are unenthusiastic; or (d) offering an inducement, are all examples of coercion or undue pressure. Be mindful that people may well feel obliged to participate if data is collected where the researcher works or volunteers. Always consider the process from the point of view of the participants. Anyone working with human participants needs to ensure that participants (a) consent freely to the research, that (b) this consent is informed, and (c) there is evidence of this. Using participant information sheets/leaflets (see Box 2) and consent forms are the best way to manage this. When a participant signs a consent form he or she is formally confirming that the participant information sheet has been read and understood (see Supplementary Material 3: Example of a Participant Information Sheet) and consent has been given to participate in the study as described. Some thought will need to be given to how the process will be managed. This is important as the consent form identifies the participant, so how will confidentiality be assured? Will the forms be kept separately from the questionnaires/ transcripts /lab notes? Who will store them and where will they be stored? How long will they be kept? 
Participants will decide on the basis of the information provided whether or not to participate in the study. Thus, it is important that the information generates interest, while clearly detailing the study and what the participant may expect. It is important to be honest. For example, if the study will take 90 minutes then this should be stated. This may well put some people off, but if the researcher is not honest about this then potential participants will have been misled and they will not have been able to provide valid consent.

\section{Box 2: What should the Participant Information Sheet include?}

- Name and contact details of the student doing the research

- Name and contact details of the research supervisor/s

- The purposes of the research (e.g. requirements of an undergraduate dissertation, part of a larger project)

- The aim of the research

- Requirements from participants (e.g. a realistic estimate of the time commitment and what the study will involve)

- An explanation of:

a) any potential risks and benefits

b) how anonymity and confidentiality will be assured

c) what the data will be used for

d) how the data will be stored and managed and who will have access to it

e) how participants can withdraw from the study

f) who to contact in case of concern or complaint

- It should include the college or university e-mail address for both student and supervisor

- It should not include private mobile or home telephone numbers or home addresses Use plain English throughout and avoid the use of jargon.

Particular care is needed if conducting research with minors or vulnerable adults. There is debate about when and to what extent children can provide informed consent and there are tensions between protecting children and ensuring their right to be heard (Gallagher, Haywood, Jones \& Milne, 2010; Lambert \& Glacken, 2011). The British Educational Research Association's (BERA) ethical guidelines are clear that children should be facilitated to give informed consent (BERA, 2011, p.6). In order to do this, information should be given to children in an appropriate and understandable way. Lambert \& Glacken (2011) provide useful examples of information leaflets tailored to children of different ages and provide 
practical examples of informing and involving children. However, a child's decision to participate in research has the status of assent rather than consent and must be accompanied by the consent of a parent or legal guardian (Felzmann Sixsmith, O'Higgins, Ni Chonnachtaigh \& Nic Gabhainn, 2010). Furthermore, it is likely that consent will be needed from gatekeepers, such as school principals or service managers, to approach potential participants. It is important also to consider the impact of the context on the consent process and the research. For example, Alderson (2004) suggests that formal settings may impact on the kind of responses children give, while Felzmann et al. (2010) cite evidence indicating that research participation during school time may be perceived as schoolwork (p.52).

Recruitment involves providing information to potential participants about the proposed research study, either directly or via an agency/organisation. If seeking permission to conduct research in an outside agency (in a company or organisation), the following tips from two experts may be helpful (see Expert Tips 1 and 2).

\section{Expert Tip 1}

Dr. Gurchand Singh, Head of An Garda Síochána Analysis Service, gives advice to students thinking of approaching an outside agency to conduct a research study.

'When making a proposal to an organisation:

1. Firstly, make sure you apply in plenty of time to give the organization time to consider the proposal. If it comes only a few weeks away from your deadline you may not receive an answer in time and this will look unprofessional from the organisation's perspective.

2. Secondly, be extremely professional as to how you approach the organization. First impressions are important. Casual e-mails with ill-thought out proposals will not create a good impression. Always be clear who you are, what you are doing and what you require from the organization. Always give an academic referee that can vouch for you.

3. Consider what is 'do-able' from the organisation's point of view and what the implications are for the organization and any potential participants.'

\section{Expert Tip 2}

Dr. Edel Healy, Head of School of Health \& Science DkIT and Chair of the School of Health \& Science Ethcis Committee, gives advice on getting research access to outside agencies.

Q. What advice could you provide to undergraduate students starting a research project which requires consent from an organisation/outside agency or 'gatekeeper'?

A. My advice to undergraduate students when starting a research project is:

1. Firstly, establish the appropriate point of contact within the organisation/outside agency. The contact person should have a clear understanding of the functioning of decisionmaking powers and should be in a position to indicate if the study can proceed, once 
ethical approval has been obtained.

2. When contacting the organisation (writing or e-mail) the student should consider carefully what is written - be sure to write in a professional manner, using appropriate and clear language so that the organisation knows what the implications are for them. Remember, students are representing their college when they make contact with outside organisations.

3. Participation Information Leaflet/Participant Consent Form: Use templates provided by their college for best practice, as they look professional and are written in user-friendly or 'plain English' language.

4. Students should ask for a letter of support from the organisation outlining what the organisation is allowing the student to do e.g. 'As part of the study you are required to write to all the sports clubs in the county.' In this way, the student has a paper trail to support what he/she is doing in case it is ever challenged.

\section{Right of Withdrawal}

It is important to remember that consent is a process that should be continuously negotiated throughout the research. Consent can be checked verbally at different points in an interview or throughout a laboratory session but attention should also be paid to non-verbal signals, such as restlessness and distraction. Researchers should consider in advance how to enable withdrawal. Lambert \& Glacken (2011, p.796) provide several concrete examples of strategies to assist children in withdrawing or stopping an interview.

Most students will be well aware that all participants have the right to withdraw their participation at any point without giving a reason. Any data provided by the withdrawing participant should be destroyed. However, facilitating this in practice is not always thought through. For example, if the student distributes a questionnaire to $100+$ people how will an individual participant's questionnaire be identified? One way to do this is to number each questionnaire. In the information sheet ask participants to note the number and to quote it if they subsequently wish to withdraw. Alternatively, participants could be asked to include an identifier such as particular digits of their mobile phone number and a parent's date of birth which may then be used to identify the questionnaire (see discussion of self-generated identifiers on page 122). This method can be useful if the questionnaires are being distributed and answered online, for example via a commercial product such as Survey Monkey.

\section{Anonymity and Confidentiality}

Both anonymity and confidentiality stem from the researcher's obligation to protect the participant's privacy (see Box 3), although the right to privacy extends 
beyond these concepts (Cohen, Manion \& Morrison, 2011). Ensuring anonymity is often relatively straightforward in the case of questionnaire based studies, as long as consent forms (if used) are collected and kept separately. However, in the case of any kind of experimental work or interview based work the researcher can link the data to the person and therefore has a duty of confidentiality to the participant. This means not disclosing information obtained in the course of the research that could be used to identify the participant. It is important to clarify at the outset who will have access to the data and how confidentiality will be managed. This can be complex in practice, for example if participants disclose information that suggests that they or others are at risk, or disclose information about criminal activity. This is especially important in work with minors, as child protection legalisation requires that such information is reported (Felzmann et al., 2010; Hutchfield \& Coren, 2011). Managing confidentiality should be carefully considered and relevant limitations made clear in advance.

To ensure confidentiality, identifying details should not accompany data at any point. This means names should never be used in field or lab notebooks or included in transcripts. But, don't forget that simply removing names does not ensure anonymity! If a student collects questionnaire data from her classmates she and other classmates may well be able to identify individuals on the basis of data about gender and age or other information. A student might interview pre-school staff in a region. If a quote is then attributed to a male participant, given the low numbers of men working in this area, there is a good chance that this participant would be identifiable. This is known as 'deductive disclosure' (see Kaiser, 2009, for a detailed discussion). As Kaiser notes, "Given that qualitative studies often contain rich descriptions of study participants, confidentiality breaches via deductive disclosure are of particular concern to qualitative researchers" (ibid., p.1632).

Confidentiality also has legal implications. Under European Data Protection legislation, 'personal data' refers to any data that can be used to identify an individual (European Commission, 2010). This identification might be revealed directly, for example via a name or e-mail address, or indirectly, through a student 
number or combination of personal details. Any personal data should be securely stored, for example on password-protected secure servers. This is especially important if the data are sensitive. Sensitive personal data include data on ethnicity, political or religious beliefs, Trade Union membership, health status and medical conditions, sexuality and offences (cited in Administrative Data Liaison Service, n.d.). It is important that both supervisors and students are familiar with, and follow, the Data Protection policies at their own institutions and consider the implications for the research project.

As far as possible, students should try to avoid collecting data that includes names or other identifiers. The more information is collected the more likely it is that an individual could be identified from it. It is therefore important to ensure that only information necessary for the project is collected. For any kind of work that involves taking two or more measurements, using names or identifiers such as student/staff number should be avoided. A useful method is to use self-generated identifiers through which the participants themselves generate a code on the basis of information known to the particpant but not to the researcher (Schnell, Bachteler \& Reiher, 2010). So, for example, a code might be the second and last letters of the participant's mother's first name and the second, fourth and last digits of the participant's phone number. This means that the participant does not need to remember a code but generates the same identifier when prompted at each data collection point. These self-generated codes are particularly useful when dealing with any potentially sensitive information. However, problems linking data can arise if participants give inconsistent information or if the codes fail to discriminate between participants (Schnell et al., 2010). It is important, therefore, to think carefully about the elements that are used to generate the code and how these are likely to work in the target population. It is a good idea to pilot this. Alternatively, the researcher may assign a code to each participant. If matching codes to names, ensure that both are never stored together and, once matched, that names or identifers are destroyed. In the audio clip (see Supplementary Material 4: Audio Clip on managing anonymity and confidentiality), one of our former undergraduate students explains how she managed anonymity in a study of motivation and adherence to an exercise programme. 


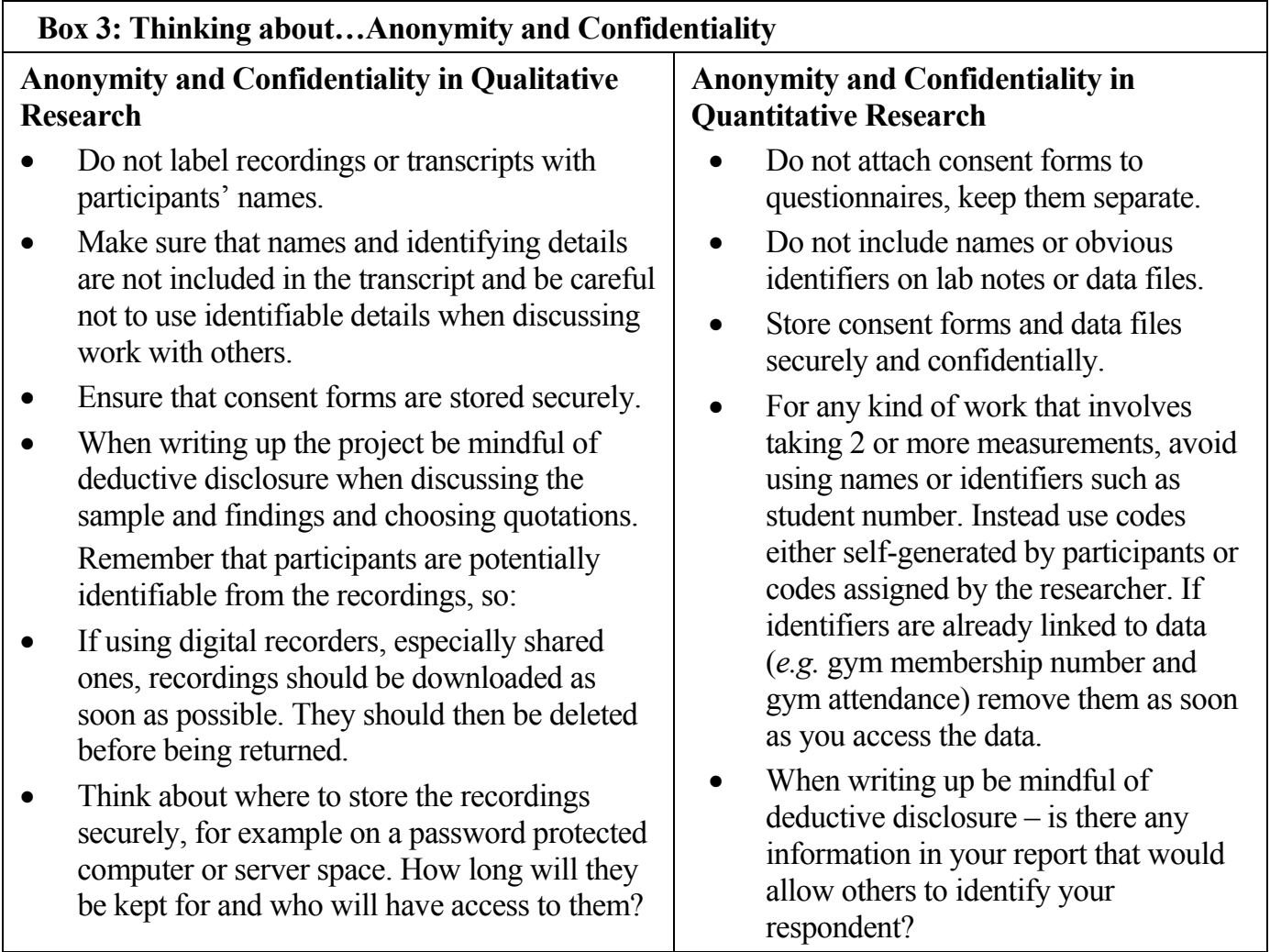

\section{Risk of Harm}

Undergraduates are both novice researchers and novices within their disciplines and cannot reasonably be expected to have the skills to manage research that potentially exposes themselves or their participants to any risk. However, even seemingly innocuous projects may contain subtle risks and it is important to assess the risk (see British Psychological Society, 2010). A key role of the supervisor is to encourage and support the student in conducting a thoughtful risk assessment of the proposed work.

\section{Physical Risks to Participants and Researchers}

It is important to consider whether a project poses any physical risk to either the participants or undergraduate researcher. For example, on one of our programmes, the BSc Health and Physical Activity, many undergraduate projects involve sport or exercise. There is always a risk associated with physical activity, however 
small, and this needs to be managed. The supplementary material has more information on how we deal with these (see Supplementary Material 5: Minimising risk in projects involving physical activity).

\section{Psychological Harm or Distress}

Psychological harm can be harder to assess and quantify than physical harm, particularly where the risk is subtle. Typically, very sensitive topics are not considered appropriate for undergraduates. For example, it is difficult to imagine justifying an undergraduate project investigating self-harm in students. It is also unlikely that an undergraduate will be in a position to work with clinical samples or other vulnerable groups, although this may happen if working as part of a larger project. However, topics including stress and health behaviours such as binge-drinking are very relevant to students of social and health studies. Remember, such projects have the potential to be distressing or even offensive to some (see Expert Tip 3). Questionnaires should be scrutinised carefully before they are distributed, even if they include existing, validated measures. Given the target population, it is important to think carefully about the questions and consider if they are likely to cause embarassment, offence or distress.

\section{Expert Tip 3}

Gail Kinman, Professor of Occupational Health Psychology at the University of Bedfordshire, gives advice on studies with the potential to cause distress.

'If your study may induce any psychological stress or anxiety it is vital to provide a thorough debrief and allow your participants sufficient time to recover. You should also consider carefully whether anyone may be psychologically distressed as a result of participating in your study. If so, information should be provided on sources of support such as University counselling helplines'.

Potentially sensitive topics are often explored using interview and focus-groups. These are usually semi-structured and, when well managed, are 'conversations with purpose'. But it can be hard to predict exactly what may emerge in the course of a conversation and how people will respond. This makes the assessment of distress more difficult (see Burr \& King, 2012). While an interviewer may ask very straightforward and non-personal questions about, say, healthy lifestyle, the participant may respond with personal and sensitive information which could be 
distressing for both interviewer and interviewee. With experience, interviewers will be able to spot potential difficulties and manage these more effectively. However, very few undergraduate researchers will have the experience to enable them to do this. Focus-groups can be particularly problematic in that participants may share information that they might later regret. It is not enough simply to ask participants to respect the confidentiality of the interview - this might not happen and even so would not prevent the participant from being distressed. It is important to seriously consider whether a focus-group is appropriate to the topic and, if it is, then the moderator/interviewer should actively manage the sessions. On the other hand, focus-groups can do more to reduce the power of the interviewer (Wilkinson, 2008) and the athmosphere may be less 'intense' than might be the case in a one-to-one interview. The key thing is to think it through and reduce the psychological risks (see Box 4). In the next audio clip a student talks about assessing risk of distress in her qualitative undergraduate dissertation on student drinking (see Supplementary Material 6: Assessing risk of distress in a qualitative undergraduate dissertation on student drinking).

\section{Box 4: Reducing the risk of distress in qualitative research.}

- If the topic is sensitive, can the question be asked in another way?

- Clarify the limits of your competence i.e. the work is being conducted by an undergraduate student. Make it very clear that the data is being collected for research purposes only, the student and supervisor cannot provide any advice or support for those concerned about the issue (e.g. binge-drinking, stress etc.). You should ensure that participants are not participating in the work in order to seek support for personal difficulties.

- Clearly state that participants are not expected to disclose any personal or sensitive information and they should not share any information they feel uncomfortable with. Seriously consider what is likely to be discussed or to come up in these interviews.

- Draw up an interview schedule to guide the interview and ensure that the questions are framed and worded appropriately.

- Ensure that you receive some training in interview techniques before you collect data. Students should have the opportunity to conduct some practice interviews and get feedback on these.

- Consider whether individual interviews or focus-groups are more appropriate to the topic.

- During the interview be alert to body language - if participants seem uncomfortable do not pursue the issue.

- Establish ongoing consent - check that participants are happy to continue with the interview. 


\section{Internet Research}

The amount of research conducted online increases year on year and this kind of research can pose very particular ethical problems (see Box 5). There is even an electronic journal devoted to this area, The International Journal of Internet Research Ethics (http://ijire.net/). Usually referred to as Internet-based research (IBR) or Internet Mediated Research (IMR), this includes use of e-mail to collect data, online surveys, analysis of social networking sites, blogs, gathering data from online communities or discussion forums (see British Psychological Society, n.d.; Convery \& Cox, 2012). IBR/IMR raises specific issues (see Expert Tip 4) in terms of consent, anonymity and confidentiality and the distinction between public and private space (Buchanan \& Hvizdak, 2009; Buchanan \& Williams, 2010; British Psychological Society, n.d.; Convery \& Cox, 2012).

\section{Box 5: Thinking about...online surveys.}

Online surveys are one of the most common forms of IBR/IMR. They offer many advantages in terms of cost and convenience, but there should be good methodological reasons to choose an online survey. Buchanan \& Hvizdak (2009) provide a detailed discussion of methodological and ethical concerns. To summarise, if proposing to use an online survey think about:

- Contacting participants, especially via mailing lists. Invitations to participate in surveys may be perceived as being intrusive or as spam, especially if there are many of them.

- Ensuring informed consent. Make sure that Participant Information is displayed before the survey starts. Include contact details in case of questions. As you won't be able to use a consent form consider including a tick box whereby participants confirm that they have read and understood the information and that by completing the questionnaire they consent to having their data used for the purposes described therein.

- Privacy and confidentiality. Do not ask participants to e-mail completed questionnaires as attachments. Using a specialised product such as SurveyMonkey is preferable.

- Checking the privacy and security policies if using a commercial product - how long is the data stored on the company's servers? Is it encrypted?

- Ensuring that respondents have the option not to answer questions.

Anyone considering using online communities, chat rooms or social networking sites as a source of data should give very serious attention to whether this is public or private space. Just because information is freely accessible on the internet does not mean that it is 'public'. Whether you are dealing with a public or private space determines whether informed consent is needed and this distinction can be blurred online (Convery \& Cox, 2012). "Researchers should be aware that participants may consider their publicly accessible internet activity to be private, or indeed the 
communication may even have been private when it was first conducted" (British Psychological Society, n.d., p.3).

If data is being collected via chat rooms, for example, then informed consent from participants is probably needed. However, each case needs to be individually assessed. Other issues to consider are the potential for harm, offence and damage to the online community. It should be remembered that many people will have an 'online identity' including a pseudonym and this will need to be protected in terms of confidentiality and deductive disclosure. Convery \& Cox (2012) have developed a very useful ethical guidance note to use in assessing internet-based projects.

\footnotetext{
Expert Tip 4

Professor Tom Buchanan at the University of Westminster, gives advice to anyone considering IBR/IMR.

First, consult existing ethical codes. While the basic principles of research ethics remain unchanged, some forms of online data collection may raise special concerns about how those principles apply. For example, what about informed consent, debriefing or privacy? Such issues are addressed in specialised ethical guides. For example, the British Psychological Society has guidelines specifically for internet research, as does the Association of Internet Researchers. Remember, in many online environments (social networks, discussion groups) individuals are going about their daily lives - and their purpose in being there is not to provide researchers with data. We need to respect the fact that observation or research participation requests may sometimes be unwelcome, and consider this when planning and executing research.
}

Second, a key principle of ethical research is scientific value - it is not ethical to waste participants' time with work that has no value. Read the existing methodological literature. Online data collection can be extremely effective, but there can be methodological and ethical considerations. Look at the work people have done in the past. Don't re-invent the wheel. There are numerous edited books, manuals, journals, papers and websites that will be useful in this. Use them to make sure your work is satisfactory in terms of scientific value.

Third, do not blindly mix online and offline data collection (e.g. emailing a survey to some participants and testing others in person). The way people answer different versions of $a$ questionnaire, for example, may differ across formats.

Fourth, consider your samples and how you have recruited them. Almost all types of sample include some form of bias that may affect generalizability of findings. Internet samples recruited in different ways will incorporate different types of bias. You need to consider this, and what it means for your findings (it doesn't automatically invalidate them!).

Finally, more from a practical than ethical perspective, keep it simple. Use existing off-the-shelf solutions, like good quality commercial online survey systems.' 


\section{Data Analysis and Writing-up}

Often students say, 'My study didn't work!' Usually this means that the hypothesis was not supported. It is important to recognise, that as long as a study has been conducted in an honest and sound way, it has 'worked' and therefore should make a contribution, however modest, to knowledge. Ethical conduct applies just as much to the analysis of data as to any other phase of the study (see Fig. 1). Analyse and report data honestly, ensuring that findings are not hidden, twisted or distorted (BERA, 2011). In qualitative work it is important to avoid simply picking and choosing findings that suit or are easy to explain. Be faithful to the data and continuously reflect on your role in the process. Flick (2009, p.41) highlights the importance of "doing justice to participants" when analysing qualitative data. This means making sure that the analysis is really grounded in the data and being careful about making judgements.

\section{CONCLUSION}

Conducting a research project is a very exciting opportunity to apply what has been learnt, and thus make a contribution to disciplinary knowledge. Hopefully this chapter has been useful in highlighting how ethical considerations are central to research, at all stages of a project. Ethical research refers not just to what you do, but also to how you think and interact. Remember, that as a novice, no-one expects you to have all the answers but you are expected to act responsibly. Do not be afraid to ask for support and for guidance. If unsure about something, or if feeling uncomfortable about what you are doing, talk to someone in your department. Ethics are not just relevant to a research project; ethical conduct is a hugely important part of professional (and everyday) life. The skills developed while conducting a dissertation will be very relevant to the rest of your life. We wish you all the very best of luck with your project.

\section{ACKNOWLEDGEMENTS}

We would like to express our deepest thanks to Anne Halliday, Lorna King, Professor Tom Buchanan, Dr. Edel Healy, Professor Gail Kinman and Dr. Gurchand Singh for their very generous contributions to this chapter. We would also like to thank the anonymous reviewers for useful feedback on a previous draft of this chapter. 


\title{
CONFLICT OF INTEREST
}

\author{
None to Declare
}

\section{SUPPLEMENTARY MATERIAL}

Supplementary material is available on the publisher's web site along with the published chapter.

\section{USEFUL RESOURCES}

a) British Educational Research Association. (2011). Ethical guidelines for educational research. Available www.bera.ac.uk/system/files/3/BERA-Ethical-Guidelines-2011.pdf.

b) Buchanan, T. \& Williams, J. E. (2010). Ethical issues in psychological research on the Internet. In: S. D.

c) Gosling \& J. A. Johnson (Eds.), Advanced methods for conducting online behavioral research (pp. 255-271). Washington, DC: American Psychological Association.

d) Felzmann, H., Sixsmith, J., O’Higgins, S., Ni Chonnachtaigh, S. and Nic Gabhainn, S. (2010). Ethical review and children's research in Ireland. Dublin: Department of Health \& Children. Available http://www.nuigalway.ie/hbsc/documents/2010_rep_ethical_ review_and_childrens_research.pdf.

e) The Internet Research Ethics Digital library, Resource Centre and Commons. Available http://internetresearchethics.org/

\section{REFERENCES}

Alderson, P. (2004). Ethics. In S. Fraser, V. Lewis, S. Ding, M. Kellett \& C. Robinson (Eds.), Doing research with children and young people (pp. 97-112). London: Sage.

Administrative Data Liaison Service (n.d.). Can a reseracher legitmately process sensitive personal data for research purposes? [Guidance Note]. ADLS. Retrieved from http://www.adls. ac.uk/publications-and-documents/

An Bord Altranais. (2007). Guidance to nurses and midwives regarding ethical conduct of nursing and midwifery research. Dublin: Author.

An Garda Síochána. (2012). Garda vetting/data protection. Retrieved from http://www.garda.ie/ FAQ/Default.aspx?FAQCategory=36.

Beauchamps, T. L. \& Childress, J. F. (2008). Principles of biomedical ethics. $6^{\text {th }}$ Edition. New York: Oxford University Press.

British Educational Research Association. (2011). Ethical guidelines for educational research. Retrieved from www.bera.ac.uk/system/files/3/BERA-Ethical-Guidelines-2011.pdf

British Psychological Society. (2010). Code of human research ethics. Retrieved from http://www.bps.org.uk/sites/default/files/documents/code_of_human_research_ethics.pdf

British Psychological Society. (n.d.). Report of the working party on conducting research on the internet: Guidelines for ethcial partice for conducting ethical research online. Retrieved 
from http://www.bps.org.uk/sites/default/files/documents/conducting_research_on_the internet-guidelines_for_ethical_practice_in_psychological_research_online.pdf.

Buchanan, E. A. \& Hvizdak, E. E. (2009). Online survey tools: Ethical and methodological concerns of human research ethics committees. Journal of Empirical Research on Human Research Ethics, 4(2), 37-48.

Buchanan, T. \& Williams, J. E. (2010). Ethical issues in psychological research on the Internet. In: S. D. Gosling \& J. A. Johnson, (Eds.), Advanced methods for conducting online behavioral research (pp. 255-271). Washington, DC: American Psychological Association.

Burr, V. \& King, N. (2012). You're in cruel England now!: Teaching research ethics through reality TV. Psychology Learning and Teaching, 11(1), 22-29.

Cohen, L., Mannion, L. \& Morrison, K. (2011). Research Methods in Education. $7^{\text {th }}$ Edition. London; New York: Routledge.

Convery, I. \& Cox, D. (2012). A review of research ethics in internet-based research. Practitioner Research in Higher Education, 6(1), 50-57.

Criminal Records Bureau (n.d.), Criminal records checks. Retrieved from http://www.businesslink.gov.uk/bdotg/action/layer?r.11=1073858787\&r.12=1073858914\&r.13=1084607697\&r.s $=$ tl\&topicId $=1084415157$.

European Commission. (2010). Protection of personal data in the European Union. [Factsheet]. European

Commission Directorate General for Justice. Retrieved from http://ec.europa.eu/justice/dataprotection/files/eujls08b-1002_-_protection_of_personnal_data_a4_en.pdf.

Felzmann, H., Sixsmith, J., O'Higgins, S., Ni Chonnachtaigh, S. and Nic Gabhainn, S. (2010). Ethical review and children's research in Ireland. Dublin: Department of Health \& Children. Retrieved from http://www.nuigalway.ie/hbsc/documents/2010_rep_ethical_ review_and_childrens_research.pdf.

Flick, U. (2009). An Introduction to Qualitative Research (4 ${ }^{\text {th }}$ ed.). London: Sage.

Gallagher, M., Haywood, S. L., Jones, M. W. \& Milne, S. (2010). Negotiating informed consent with children in school-based research: A critical review. Children and Society, 24, 471482.

Government of Ireland. (1988). Data protection Act 1988, No. 25. Retrieved from http://www.irishstatutebook.ie/1988/en/act/pub/0025/index.html

Government of Ireland. (2003). Data protection (amendment) Act 2003, No. 6. Retrieved from http://www.irishstatutebook.ie/2003/en/act/pub/0006/index.html

Hunter, D. (2010). Locating ethics in research. In J. Hughes (Ed.), European Textbook on Ethics in Research. (pp. 11-32). Luxembourg, Publications Office of the European Union. Retrieved from http://www.eurosfaire.prd.fr/7pc/doc/1292233423_textbook_on_ethics_report_en.pdf

Hutchfield, J. \& Coren, E. (2011). The child's voice in service evaluation: ethical and methodological issues. Child Abuse Review, 20, 173-186.

Kaiser, K. (2009). Protecting respondent confidentiality in qualitative research. Qualitative Health Research, 19(11), 1632-1641.

Lambert, V. \& Glacken, M. (2011). Engaging with children in research; Theoretical and practical implications of negotiating informed consent/assent. Nursing Ethics, 18(6), 781-801.

McCarthy, J. (2003). Principlism or narrative ethics: must we choose between them? Medical Humanities, 29, 65-71. Retrieved from http://mh.bmj.com/content/29/2/65.full.pdf.

Miller, R. B. (2003). How the Belmont Report fails. Essays in Philosophy, 4 (2), Article 6. Retrieved from http://commons.pacificu.edu/eip/vol4/iss2/6. 
Perlman, D. (2004). Ethics in clinical research: A history of human subject protections and practical implementation of ethical standards. SoCRA Source, 37-41. Retrieved from www.socra.org/pdf/200405_Ethics_Clinical_Research_History

Royal Irish Academy. (2010). Ensuring integrity in Irish research: A discussion document. Dublin: Author. Retrieved from www.ria.ie/getmedia/28404e5c-4839-4408-9d40e2a3770c775a/ensuring-integrity-in-irish-research.pdf.aspx

Schnell, R., Bachteler, T. \& Reiher, J. (2010). Improving the use of self-generated identification codes. Evaluation Review, 34(5), 391-418.

Steneck, N. (2006). Fostering integrity in research: definitions, current knowledge, and future directions. Science and Engineering Ethics, 12(1), 53-74.

The National Commission for the Protection of Human Subjects of Biomedical and Behavioral Research (1979). The Belmont Report: Ethical Principles and Guidelines for the Protection of Human Subjects of Research. Retrieved from http://ohsr.od.nih.gov/mpa/belmont.

Wilkinson, S. (2008). Focus groups. In J.A. Smith (Ed). Qualitative Psychology: A Practical Guide to Research Methods ( $2^{\text {nd }}$ ed). London: Sage.

World Medical Association. (1964/2008). Declaration of Helsinki: Ethical principles for medical research involving human subjects. Retrieved from http://www.wma.net/en/30publications /10policies/b3/.

Wrestler, K.L. (2011). Publishing ethical research: a step-by-step overview. Journal of Counselling \& Development, 89 (3), 301-307. 